\title{
The Relationship Between Musculoskeletal Injury and Objectively Measured Physical Activity Levels: A Critically Appraised Topic
}

\author{
Amy R. Barchek, Shelby E. Baez, Matthew C. Hoch, and Johanna M. Hoch
}

\begin{abstract}
Clinical Scenario: Physical activity is vital for human health. Musculoskeletal injury may inhibit adults from participating in physical activity, and this amount may be less than adults without a history of musculoskeletal injury. Clinical Question: Do individuals with a history of ankle or knee musculoskeletal injury participate in less objectively measured physical activity compared with healthy controls? Summary of Key Findings: Four studies were included. Two studies concluded patients who have undergone an anterior cruciate ligament reconstruction (ACLR) spent less time in moderate to vigorous physical activity levels when compared with healthy controls, but still achieved the daily recommended amount of physical activity. One study determined that participants with CAI took fewer steps per day compared with the control group. The fourth study determined patients with patellofemoral pain were less physically active than healthy controls as they took fewer steps per day and spent less time participating in mild and high activity. Clinical Bottom Line: There is consistent, high quality evidence that demonstrates individuals with a history of ankle or knee musculoskeletal injury participate in less objectively measured physical activity compared with healthy individuals. Strength of Recommendation: Due to nature of study designs of the included articles in this critically appraised topic, we recommend a grade of $3 \mathrm{~B}$.
\end{abstract}

Keywords: ACL injury, ankle injury, chronic disease, exercise

\section{Clinical Scenario}

According to the American College of Sports Medicine and the American Heart Association, it is recommended that adults aged 18-65 years should spend a minimum of 30 minutes per day for 5 days each week participating in moderate physical activity or 20 minutes per day for 2 days each week participating in vigorous physical activity. ${ }^{1,2}$ Furthermore, the recommended average daily steps needed to maintain health for an adult is 10,000 steps per day ${ }^{3}$; however, a study conducted in 2008 estimated that less than $10 \%$ of adults meet the recommended guidelines for daily physical activity. ${ }^{2}$ It is important that adults reach these recommendations, as physical activity can aid in the prevention of coronary heart disease, type 2 diabetes, and different types of cancer as well as prevent recurring or chronic injuries. ${ }^{4}$ One factor that may cause adults to participate in less physical activity is musculoskeletal injury including injuries to the knee ${ }^{5-7}$ and ankle. ${ }^{8}$ Most often subjective measures of physical activity have been utilized in these populations, including the Tegner activity scale ${ }^{9}$ and the Marx activity scale. ${ }^{10}$ However, most recently objective measures of physical activity have been used to determine physical activity levels in patients with a history of musculoskeletal injury. These findings are pertinent to patient care, as an understanding of how these injuries may affect a person's physical activity can help clinicians educate their patients on the importance of participating in physical activity to reduce the risk of chronic disease development associated with physical inactivity. ${ }^{4,6-8}$ Therefore, the purpose of this critically appraised topic (CAT) was to synthesize and critically appraise the current research that examines

Barchek, Baez, Hoch and Hoch are with the Department of Athletic Training and Clinical Nutrition, College of Health Sciences, University of Kentucky, Lexington, KY. Barchek (amy.barchek@uky.edu) is corresponding author. objectively measured physical activity levels in patients who have a history of ankle or knee injury compared with healthy controls.

\section{Focused Clinical Question}

Do individuals with a history of ankle or knee injury participate in less objectively measured physical activity compared with healthy controls?

\section{Search Strategy}

A computerized search was completed in October 2018. The following search terms were used:

- Patient/Group: Lower-extremity injury (knee OR ankle OR knee injury OR ankle injury OR knee pain OR ankle pain)

- Intervention: None

- Comparison: Healthy controls OR healthy (not osteoarthritis OR arthritis OR elderly OR older OR amputation OR aging OR diabetes OR stroke)

- Outcomes: Objective measured physical activity OR step counts OR moderate to vigorous physical activity OR MVPA OR pedometer OR fitness tracker AND physical activity

\section{Sources of Evidence Searched}

- EBSCOhost

- Academic Search Complete

- CINAHL Full Text

- MEDLINE

- SPORTDiscus 


\section{Inclusion Criteria}

- Studies that objectively measured physical activity levels (ie, moderate to vigorous physical activity levels or steps per day).

- Studies that compared outcomes of participants with a knee or ankle injury to healthy controls

- Studies published in the English language

- Studies that only included adults

- Studies published between 2009 and present

\section{Exclusion Criteria}

- Studies that included adolescents

- Studies that included patients who underwent total joint reconstruction, osteoarthritis, elderly, patients with diabetes, amputees, or stroke

\section{Evidence Quality Assessment}

Validity of the articles found was determined using the strengthening the reporting of observational studies in epidemiology (STROBE) ${ }^{11}$ statement. Prior to review, the authors met and discussed each item on the STROBE. It was decided that numbers 17 and 22 would be removed from the instrument prior to appraisal due to not being applicable to the purpose of this CAT. The maximum number of quality points on the STROBE was 20. Two authors (A.B. and J.H.) reviewed and scored each article independently. Following the independent review, the 2 authors met and reached agreement on the appraisal and quality of each study. If a disagreement arose, a third reviewer (S.B.) was consulted to discuss and come to a consensus.

\section{Results of Search}

The search of the literature yielded 49 studies (Figure 1). After a review of the abstracts, 45 studies were excluded as they did not meet the inclusion criteria for this CAT. Four studies ${ }^{5-8}$ were included, 3 case-control studies and 1 cross-sectional study. Characteristics of these studies are detailed in Table 1.

\section{Results of Evidence Quality Assessment}

The scores on the STROBE ranged from 16 to 19 . None of the included articles ${ }^{6-8}$ discussed any efforts to address sources of potential bias. Bell et al, ${ }^{6}$ Hubbard-Turner and Turner, ${ }^{8}$ and Glaviano et $\mathrm{al}^{5}$ did not provide a proper description of the setting, locations, or relevant dates of the study. Also, Hubbard-Turner and Turner $^{8}$ did not provide a hypothesis or explain how their study size was arrived at.

\section{Clinical Bottom Line}

There is consistent, high-quality evidence that demonstrates individuals with a history of ankle or knee injury participate in less objectively measured physical activity compared with healthy individuals. Due to nature of study designs of the included articles in this CAT, we recommend a grade of B as recommended by the Oxford Centre of Evidence-Based Medicine. ${ }^{12}$

\section{Implications for Practice, Education, and Future Research}

The results of this CAT revealed consistent, high-quality evidence that compared objectively measured physical activity between patients with a history of ankle or knee injury with healthy controls. Two studies ${ }^{6,7}$ investigated moderate to vigorous physical activity (MVPA) levels with similar methodologies using a wrist-worn accelerometer, specifically an ActiGraph wGT3X-BT unit (ActiGraph Corp, Pensacola, FL). Bell et al ${ }^{6}$ investigated the differences in average time spent in MVPA and daily step counts in patients who have been cleared to return from an anterior cruciate ligament reconstruction (ACLR) and healthy controls. The authors secondary purpose was to investigate the relationship between MVPA levels step counts and subjective measures of physical activity. The participants wore the

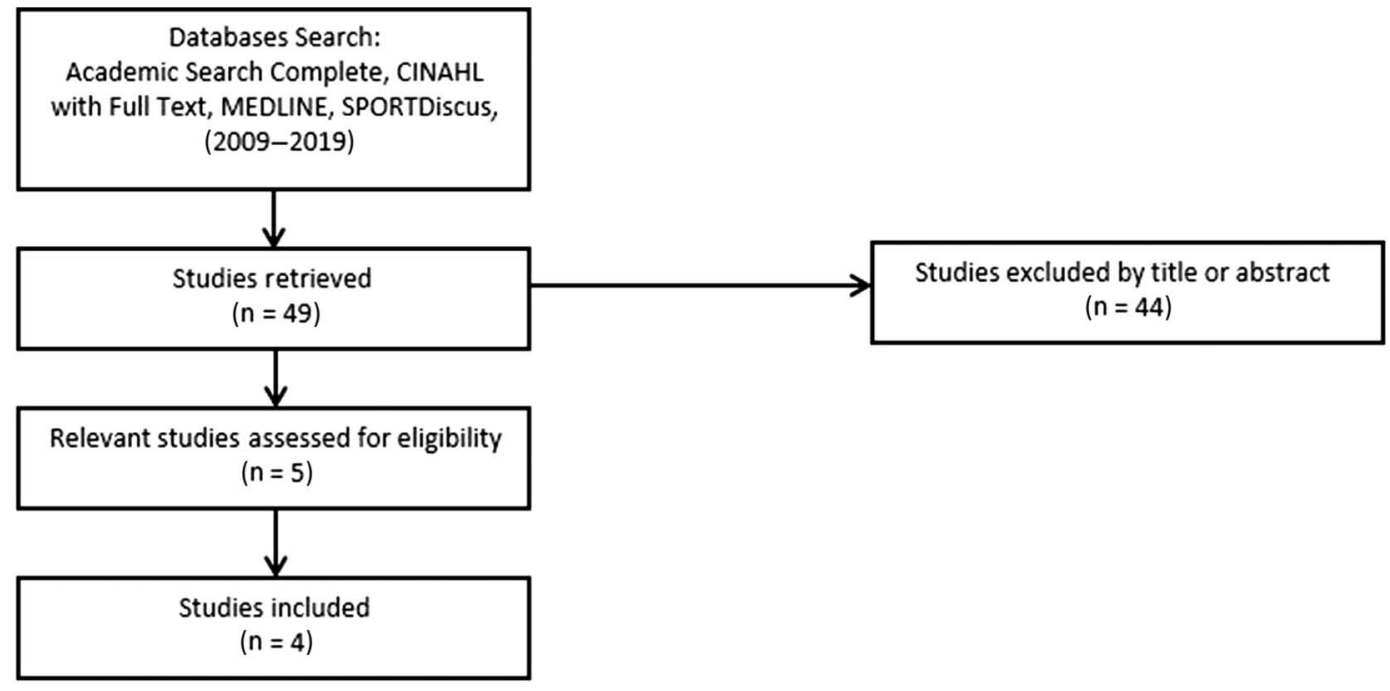

Figure 1 - Summary of search history and included studies. 
Table 1 Characteristics of Included Studies

\begin{tabular}{|c|c|c|c|c|}
\hline Author & Bell et $\mathrm{al}^{6}$ & Hubbard-Turner et $\mathrm{al}^{8}$ & Kuenze et $\mathrm{al}^{7}$ & Glaviano et al $^{5}$ \\
\hline Study title & $\begin{array}{l}\text { Objectively measured } \\
\text { physical activity in patients } \\
\text { after anterior cruciate } \\
\text { ligament reconstruction }\end{array}$ & $\begin{array}{l}\text { Physical activity levels in college } \\
\text { students with chronic ankle } \\
\text { instability }\end{array}$ & $\begin{array}{l}\text { Relationship between } \\
\text { physical activity and } \\
\text { clinical outcomes after } \\
\text { ACL reconstruction }\end{array}$ & $\begin{array}{l}\text { Physical activity levels in } \\
\text { individuals with and without } \\
\text { patellofemoral pain }\end{array}$ \\
\hline Study design & Cross-sectional study & Case-control study & Case-control study & Case-control study \\
\hline Level of evidence & 3 & 3 & 3 & 3 \\
\hline Participants & $\begin{array}{l}\text { A total of } 33 \text { participants } \\
\text { with history of unilateral or } \\
\text { bilateral ACLR and } 33 \\
\text { matched healthy controls }\end{array}$ & $\begin{array}{l}\text { A total of } 20 \text { participants with } \\
\text { unilateral CAI and } 20 \text { healthy } \\
\text { participants }\end{array}$ & $\begin{array}{l}\text { A total of } 31 \text { ACLR par- } \\
\text { ticipants and } 31 \text { matched } \\
\text { controls }\end{array}$ & $\begin{array}{l}\text { A total of } 20 \text { participants with } \\
\text { PFP and } 20 \text { healthy controls }\end{array}$ \\
\hline Inclusion criteria & $\begin{array}{l}\text { Undergone ACLR within } \\
5 \mathrm{y} \text { and fully cleared }\end{array}$ & $\begin{array}{l}\text { CAI: history of unilateral ankle } \\
\text { sprain, frequent sensation of the } \\
\text { ankle "giving way," pain, feeling } \\
\text { of instability, decreased function } \\
\text { Healthy: no previous musculo- } \\
\text { skeletal injury or surgery to either } \\
\text { lower-extremity } \\
\text { All: report that they were healthy } \\
\text { and had no illness or chronic } \\
\text { diseases that would impair their } \\
\text { normal physical activity levels }\end{array}$ & $\begin{array}{l}\text { Undergone ACLR surgery } \\
\text { in the past } 5 \mathrm{y} \text { and has been } \\
\text { fully cleared for return by a } \\
\text { medical professional }\end{array}$ & $\begin{array}{l}\text { Knee pain for more than } 3 \text { mo, } \\
\text { less than } 85 \text { points on the Anterior } \\
\text { Knee Pain Scale, pain with a } \\
\text { minimum of } 2 \text { of the following } \\
\text { tasks: jumping, kneeling, pro- } \\
\text { longed sitting, squatting, running, } \\
\text { stair climbing, and pressure on } \\
\text { patella during contraction of the } \\
\text { quadriceps }\end{array}$ \\
\hline Exclusion criteria & $\begin{array}{l}\text { ACLR: participants who } \\
\text { had experienced signifi- } \\
\text { cant surgical complica- } \\
\text { tions resulting in extended } \\
\text { medical care or a second } \\
\text { procedure, posterior cruci- } \\
\text { ate ligament or posterolat- } \\
\text { eral corner reconstruction } \\
\text { at the time of the ACLR } \\
\text { Healthy: history of signif- } \\
\text { icant lower-extremity } \\
\text { injury that resulted in } \\
\text { surgery }\end{array}$ & $\begin{array}{l}\text { Ankle sprain within } 6 \text { wk of the } \\
\text { start of the study, history of sur- } \\
\text { gery, or fracture to either lower- } \\
\text { extremity, previous ankle sprain } \\
\text { to the ankle contralateral to the } \\
\text { chronically unstable ankle }\end{array}$ & $\begin{array}{l}\text { History of chronic or acute } \\
\text { neurologic disorder, car- } \\
\text { diopulmonary disease, or } \\
\text { any other medical condi- } \\
\text { tion that may limit the } \\
\text { ability to participate in } \\
\text { MVPA. Participants with } \\
\text { posterior cruciate ligament } \\
\text { or posterolateral corner } \\
\text { reconstruction }\end{array}$ & $\begin{array}{l}\text { Previous knee surgery; ligamen- } \\
\text { tous instability; additional sources } \\
\text { of anterior knee pain (patella } \\
\text { tendinopathy, patella subluxation, } \\
\text { bursitis, etc); history of back, hip, } \\
\text { or ankle injury; neurological im- } \\
\text { pairments that would affect gait }\end{array}$ \\
\hline $\begin{array}{l}\text { Intervention } \\
\text { investigated }\end{array}$ & None & None & None & None \\
\hline Outcome measures & $\begin{array}{l}\text { Time spent in MVPA (in } \\
\text { minutes), daily step count }\end{array}$ & Total number of weekly steps & $\begin{array}{l}\text { Time spent in MVPA (in } \\
\text { minutes), bouts of MVPA } \\
\text { longer than } 10 \mathrm{~min}\end{array}$ & $\begin{array}{l}\text { Steps per day; minutes of mild, } \\
\text { moderate, and high activity }\end{array}$ \\
\hline Main findings & $\begin{array}{l}\text { Participants in the ACLR } \\
\text { group spent less time in } \\
\text { MVPA }(79.37 \\
[23.95] \mathrm{min} / \mathrm{d}) \text { than } \\
\text { healthy controls }(93.12 \\
[23.94] \mathrm{min} / \mathrm{d}, P=.02) \text { and } \\
\text { took fewer daily steps } \\
(8158[2780] \text { steps/d) than } \\
\text { healthy controls }(9769 \\
[2785] \text { steps } / \mathrm{d}, P=.02)\end{array}$ & $\begin{array}{l}\text { Participants with CAI were less } \\
\text { physically active }(6694.47 \\
{[1603.35] \text { steps/d) than healthy }} \\
\text { controls }(8831.01 \\
[1290.01] \text { steps/d, } P=.04)\end{array}$ & $\begin{array}{l}\text { Participants in the ACLR } \\
\text { group spent less time in } \\
\text { MVPA (553 [175] min/ } \\
\text { wk) than healthy controls } \\
(658[161] \mathrm{min} / \mathrm{wk}, \\
P=.05)\end{array}$ & $\begin{array}{l}\text { Patients with PFP took fewer steps } \\
\text { per day }(8629.7[1665.3] \text { steps/d) } \\
\text { than healthy controls }(12,042.4 \\
\text { [3878.7] steps/d, } P=.004) \text {. Parti- } \\
\text { cipants with PFP participated in } \\
\text { fewer daily minutes of mild } \\
\text { activity }(163.3[38.1], P=.007) \\
\text { and high activity }(17.8[7.9], \\
P=.012) \text { than healthy control } \\
\text { participants }(\text { mild }=203.7[38.7] \text {, } \\
\text { high }=27.9[12.3]) .\end{array}$ \\
\hline Validity score & 18 & 16 & 19 & 18 \\
\hline $\begin{array}{l}\text { Support for the } \\
\text { answer }\end{array}$ & Yes & Yes & Yes & Yes \\
\hline
\end{tabular}

Abbreviations: ACLR, anterior cruciate ligament reconstruction; CAI, chronic ankle instability; MVPA, moderate to vigorous physical activity; PFP, patellofemoral pain.

ActiGraph accelerometer for 7 consecutive days for at least 10 hours per day. The authors observed patients with a history of ACLR spent overall less time in MVPA (79.37 [23.95] min/d) and had fewer daily step counts (8158 [2780] steps/d) than the healthy controls (93.12 [23.94] min/d and 9769 [2785] steps/d).
There were no relationships between objective measures of physical activity (MVPA or step counts) and subjective measures of physical activity (Marx or Tegner scale). ${ }^{6}$

Kuenze et $\mathrm{al}^{7}$ observed the relationship between objectively measured MVPA and self-reported physical activity and knee 
function in patients who have undergone ACLR and included a secondary aim to investigate differences in MVPA levels between those with a history of ACLR and healthy controls. In similar methodology to Bell et al, ${ }^{6}$ the participants wore an ActiGraph wGT3X-BT (ActiGraph Corp) accelerometer for 7 days for a minimum of 10 hours per day. The participants also completed self-report measures (the International Knee Documentation Committee Scale and the Knee Osteoarthritis Outcome Score, along with subjective measures of physical activity and knee strength measures. Interestingly, there were no relationships between selfreported measures of knee function (International Knee Documentation Committee Scale and the Knee Osteoarthritis Outcome Score), subjective measures of physical activity or knee strength measurements. The authors determined that patients included in the ACLR groups spent less time (553 [175] min/wk) in MVPA than the healthy controls $(658[161] \mathrm{min} / \mathrm{wk})$.

Glaviano et $\mathrm{al}^{5}$ examined the difference in physical activity levels in patients with a history of patellofemoral pain compared with healthy controls. All participants wore a FitBit Charge HR (FitBit Inc, San Francisco, CA) on their wrist for 2 consecutive weeks, and the authors assessed each participant's steps per day and minutes of mild, moderate, and high activity levels. It was observed that the patients in the patellofemoral pain group took fewer overall steps per day (8629.7 [1665.3] steps/d) and completed fewer minutes of mild (163.3 [38.1] $\mathrm{min} /$ day), moderate (11.6 [6.7] $\mathrm{min} / \mathrm{d})$, and high (17.8 [7.9] $\mathrm{min} / \mathrm{d})$ activity levels per day compared with the healthy controls $(12,042.2$ [3878.7] steps/d, 203.7 [38.7] $\mathrm{min} / \mathrm{d}, 16.0$ [6.1] $\mathrm{min} / \mathrm{d}$, and 27.9 [12.3] $\mathrm{min} / \mathrm{d}$, respectively).

Finally, Hubbard-Turner and Turner ${ }^{8}$ assessed the difference in total steps taken in a week between healthy controls and participants with CAI, the difference of total weekly steps between male and female participants with CAI, and the relationship between physical activity levels and ankle laxity. Each participant wore a pedometer for 7 days on their hip. Participants were instructed to wear the pedometer at all times except for sleeping, swimming, or showering and were instructed to keep a daily step $\log$ to document their steps each day. The results indicated the CAI group took fewer steps (6694.47 [1603.35] steps/d) when compared with the controls (8831.01 [1290.01] steps/d). There was no significant difference found between sexes, and ankle laxity was overall greater for the CAI group and was correlated to physical activity levels.

Objectively measured physical activity appears to be more accurate than subjective reports. Bell et $\mathrm{al}^{6}$ found that patients after ACLR are less physically active than healthy individuals, spend less time in MVPA, and have a lower step count when measured objectively. However, there were no differences in subjective measures of physical activity between these 2 groups. ${ }^{6}$ Furthermore, both studies that included ACLR participants found that there was no relationship between subjective and objective measures of physical activity. ${ }^{6,7}$ Both authors recommended that objectively measured physical activity levels be incorporated into the rehabilitation process for patients following an ACLR to aid in obtaining the treatment goals. ${ }^{6,7}$ The authors of these studies used ActiGraph wGT3X-BT units to measure physical activity levels; however, there are other less expensive or easily accessible options. For example, smartphones and smartwatches often have a built-in pedometer that patients could use to track their steps per day. Also, a standard pedometer can be very inexpensive, averaging cost about $\$ 5$ per unit. Glaviano et $\mathrm{al}^{5}$ utilized a FitBit Charge HR (FitBit Inc) that average cost about $\$ 75$ to $\$ 150$ per unit. Although there are a range of options and costs for equipment to objectively measure physical activity, the addition of an objective measure into a treatment plan will ensure clinicians that patients true activity levels are being measured and that they are meeting the recommended guidelines for physical activity.

The results of this CAT suggest patients who have sustained an ankle or knee injury become less physically active and thus may be at risk for negative health consequences associated with physical inactivity. However, patients may not be aware of the risks associated with an inactive lifestyle. Therefore, it is important that clinicians educate their patients on the benefits of a physically active lifestyle, with the impetus to either improve their patient's participation in physical activity or promote the maintenance of their patient's physical activity levels to maintain a healthy lifestyle. Clinicians should monitor physical activity levels with objective measures of physical activity as subjective measures may not be entirely representative of the patient's true physical activity levels. Future research should examine mechanisms to improve physical activity in larger populations of people with a history of musculoskeletal health conditions. This may include educational strategies to improve physical activity participation, which has been done in the osteoarthritis literature. ${ }^{13}$ Future research should also make efforts to address bias that may occur when utilizing an objective assessment of physical activity. Finally, future research should consider the time of year that the data are collected, as the time of year may impact physical activity practices.

\section{References}

1. Haskell WL, Lee IM, Pate RR, et al. Physical activity and public health: updated recommendation for adults from the American College of Sports Medicine and the American Heart Association. Med Sci Sports Exerc. 2007;39(8):1423-1434. doi:10.1249/mss.0b013e3180616b27

2. Troiano RP, Berrigan D, Dodd KW, Masse LC, Tilert T, McDowell M. Physical activity in the United States measured by accelerometer. Med Sci Sports Exerc. 2008;40(1):181-188. doi:10.1249/mss. 0b013e31815a51b3

3. Tudor-Locke C, Craig CL, Brown WJ, et al. How many steps/day are enough? For adults. Int J Behav Nutr Phys Act. 2011;8:79. PubMed ID: 21798015 doi:10.1186/1479-5868-8-79

4. Lee IM, Shiroma EJ, Lobelo F, et al. Effect of physical inactivity on major non-communicable diseases worldwide: an analysis of burden of disease and life expectancy. Lancet. 2012;380(9838):219-229. PubMed ID: 22818936 doi:10.1016/S0140-6736(12)61031-9

5. Glaviano NR, Baellow A, Saliba S. Physical activity levels in individuals with and without patellofemoral pain. Phys Ther Sport. 2017;27:12-16. PubMed ID: 28780340 doi:10.1016/j.ptsp.2017. 07.002

6. Bell DR, Pfeiffer KA, Cadmus-Bertram LA, et al. Objectively measured physical activity in patients after anterior cruciate ligament reconstruction. Am J Sports Med. 2017;45(8):1893-1900. PubMed ID: 28419817 doi: $10.1177 / 0363546517698940$

7. Kuenze C, Cadmus-Bertram L, Pfieffer K, et al. Relationship between physical activity and clinical outcomes after ACL reconstruction. J Sport Rehabil. 2019:28(2):180-187. PubMed ID: 29140161 doi:10. 1123/jsr.2017-0186

8. Hubbard-Turner T, Turner MJ. Physical activity levels in college students with chronic ankle instability. J Athl Train. 2015;50(7):742747. PubMed ID: 25898110 doi:10.4085/1062-6050-50.3.05

9. Tegner Y, Lysholm J. Rating systems in the evaluation of knee ligament injuries. Clin Orthop Relat Res. 1985;198:43-49. 
10. Marx RG, Stump TJ, Jones EC, Wicklewlcz TL, Warren RF. Development and evaluation of an activity rating scale for disorders of the knee. Am J Sports Med. 2001;29(2):213-218. PubMed ID: 11292048 doi:10.1177/03635465010290021601

11. von Elm E, Altman DG, Egger M, et al. The strengthening the reporting of observational studies in epidemiology (STROBE) statement: guidelines for reporting observational studies. Int J Surg. 2014;12(12):1495-1499. PubMed ID: 25046131 doi:10.1016/ j.ijsu.2014.07.013
12. Oxford Centre for Evidence-based Medicine-Levels of Evidence. CEBM. https://www.cebm.net/2009/06/oxford-centre-evidence-basedmedicine-levels-evidence-march-2009/. Published March 2009. Accessed December 19, 2019.

13. Hunter DJ, Eckstein F. Exercise and osteoarthritis. J Anat. 2009; 214(2):197-207. PubMed ID: 19207981 doi:10.1111/j.1469-7580. 2008.01013.x 